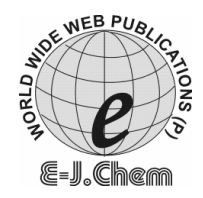

ISSN: 0973-4945; CODEN ECJHAO

E $==y_{0}$ (C)

E-Journal of Chemistry

http://www.e-journals.net

2009, 6(4), 1133-1138

\title{
Syntheses, Evaluation and Characterization of Some 1, 3, 4-Oxadiazoles as Antimicrobial Agents
}

\author{
NITI BHARDWAJ*, S.K. SARAF, PANKAJ SHARMA ${ }^{\S}$ and PRADEEP KUMAR ${ }^{\#}$, \\ Northern India Engineering College, Lucknow, India. \\ ${ }^{\S}$ Raj Kumar Goel Institute of Technology, Ghaziabad, India. \\ \#PES College of Pharmacy, Bangalore, India. \\ pradeep_alpine@yahoo.co.in
}

Received 9 March 2009; Accepted 15 April 2009

\begin{abstract}
Oxadiazoles show various biological activities and have been synthesized from different compounds. 1,3,4-oxadiazole is popularly known for its antimicrobial, anti-inflammatory, pesticidal and antihypertensive activities etc. It is well known that the synthesis of heterocyclic compounds tend to contain multi-structure in a molecule. The ring formation involves the condensation reaction. The challenge is to develop the ring system by incorporating the indole nucleus into it through the proposed reaction scheme. There are two free positions for the substitution in the oxadiazole ring system. In this study, it was planned to incorporate the oxadiazole ring system into indole ring. Synthesis of derivatives of 1,3,4-oxadiazoles from different benzaldehydes Characterization of the synthesized compounds along with their antimicrobial activity on different strains.
\end{abstract}

Keywords: Oxadiazole, Heterocyclic compounds, Chemotherapy, Antibacterial and Antifungal

\section{Introduction}

The earliest evidence of successful chemotherapy is from ancient Peru, where the Indians used bark from the Cinchona tree to treat malaria. Modern chemotherapy has been dated to the work of Paul Ehrlich in Germany, who sought systematically to discover effective agents to treat trypanosomiasis and syphilis. Ehrlich postulated that it would be possible to find chemicals that were selectively toxic for parasites but not toxic to humans. Progress in the development of novel antibacterial agents has been great, but the development of effective, nontoxic antifungal and antiviral agents has been slow. Amphotericin B, isolated in the1950s, remains an effective antifungal agent, although newer agents such as fluconazole are now widely used. An antimicrobial is a substance that kills or inhibits the growth of microbes such as bacteria (antibacterial activity), fungi (antifungal activity) and viruses 
(antiviral activity).Any attempt to discuss the chemotherapeutic properties of heterocyclic compounds must, of necessity, be confined to a limited aspect of the subject. Therefore, the present discussion will be limited to monocyclic compounds with 5-membered ring. By definition, this includes not only compounds with a single 5-membered ring but also substances with two or more rings, one of which must be six membered.



Figure 1. Sites of action of different antimicrobial agent's PABA, DHFA, THFA.

The polyene antibiotics, which apparently act by binding to membrane sterols, contain a rigid hydrophobic center and a flexible hydrophilic section. Structurally, polyenes are tightly packed rods held in rigid extension by the polyene portion. They interact with fungal cells to produce a membrane-polyene complex that alters the membrane permeability, resulting in internal acidification of the fungus with exchange of $\mathrm{K}^{+}$and sugars; loss of phosphate esters, organic acids, nucleotides; and eventual leakage of cell protein. In effect, the polyene makes a pore in the fungal membrane and the contents of the fungus leak out. Although numerous polyene antibiotics have been isolated, only amphotericin B is used systemically. Nystatin is used as a topical agent and primaricin as an ophthalmic preparation. A number of other agents interfere with the synthesis of fungal lipid membranes. These agents belong to a class of compounds referred to as imidazoles: miconazole, ketoconazole, clotrimazole, and fluconazole. These compounds inhibit the incorporation of subunits into ergosterol and may also directly damage the membrane.

The development of antifungal agents has lagged behind that of antibacterial agents. This is a predictable consequence of the cellular structure of the organisms involved. This difficulty complicates experiments designed to evaluate the in vitro or in vivo properties of a potential antifungal agent.

1,3,4-Oxadiazoles show various biological activities and have been synthesized from different compounds. Many reaction schemes were followed for the synthesis of the ring and 1,3,4-oxadiazole ring showed diversity in biological activity. 1,3,4-oxadiazole is popularly known for its antimicrobial, anti-inflammatory, pesticidal, antihypertensive activities etc. It is well known that the synthesis of heterocyclic compounds tend to contain multi-structure in a molecule. The ring formation involves the condensation reaction. In each step, a water molecule is formed. 


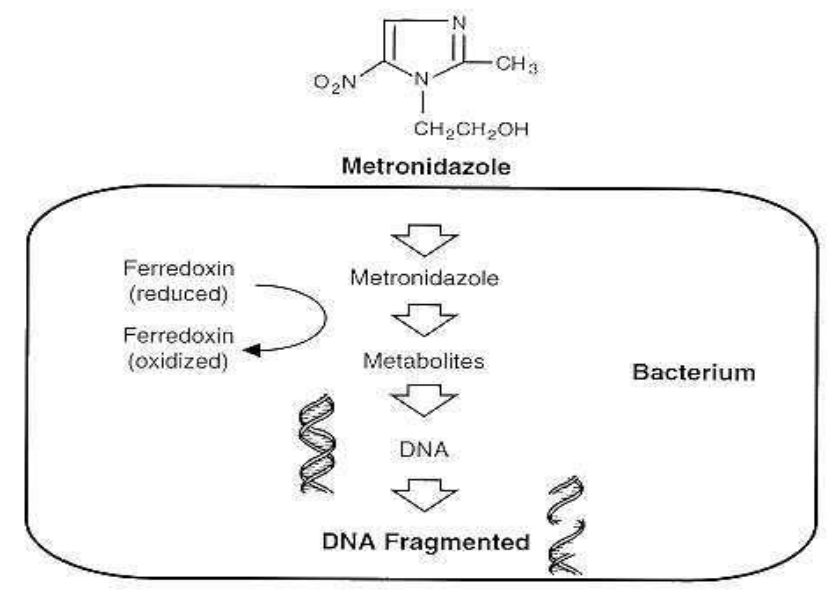

Figure 2. Structure of metronidazole and its mechanism of action.

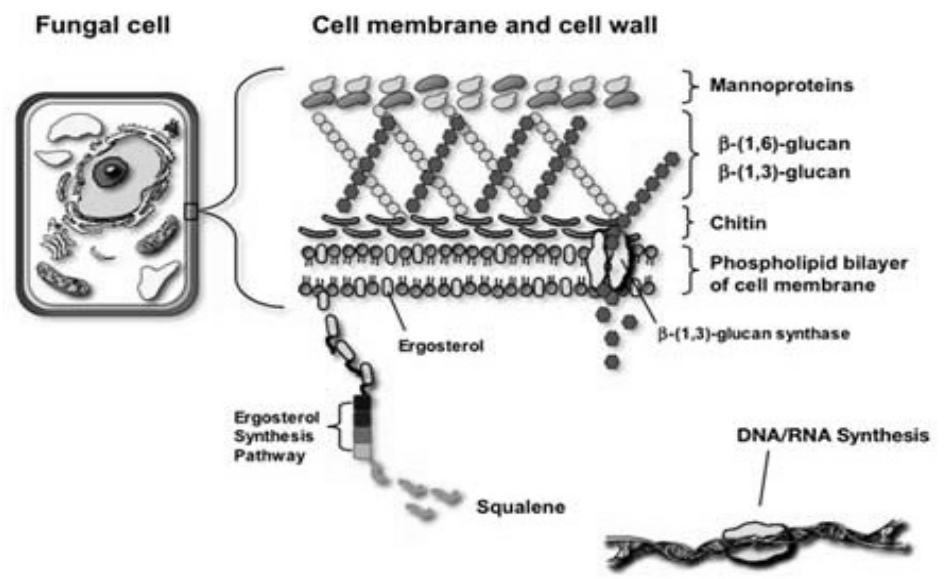

Figure 3. Fungal cell structure.

The challenge is to develop the ring system by incorporating the indole nucleus into it through the proposed reaction scheme. There are two free positions for the substitution in the oxadiazole ring system ${ }^{1-5}$. In this study, it was planned to incorporate the oxadiazole ring system into indole ring, as it has not been reported earlier. Synthesis of derivatives of 1,3,4oxadiazoles from different benzaldehydes. Characterization of the synthesized compounds along with their antimicrobial activity on different strains

\section{Experimental}

Materials and methods ${ }^{6,7}$

Other than the procedure involved, we used various instruments to authenticate our study. IR spectra were recorded on Shimadzu Infra-red spectrophotometer. Characteristic peaks observed were of $\mathrm{NH}-\mathrm{str}, \mathrm{C}=\mathrm{O}$, $-\mathrm{CH}$ str. Mass spectra were recorded on Jeol/ SX-102/ DA600 FABMS spectroscopy from C.D.R.I, Lucknow. Melting points were determined by Thiel's tube method. The purity of compounds was confirmed by thin layer chromatography using prepared TLC plates and a solvent system of 5\% methanol: chloroform. The spots 
were developed in both UV chamber (long and short wavelength) and iodine chamber. Antimicrobial activity of the compounds was performed by Punched-hole method against MTCC 441 (Bacillus subtilis), MTCC 1430 (Staphylococcus aureus), MTCC 424 (Pseudomonas aeruginosa), MTCC 1573 (Escherichia coli) and MTCC 2546 (A. niger) respectively. Standard procedure was followed from "The Pharmacopoeia of India". The standard drugs used were norfloxacin and fluconazole.

Synthesis of indole-2-carboxylate (an ester) from indole-2-carboxylic acid

An ice bath was prepared and $50 \mathrm{~mL}$ of methanol in flat bottom flask was kept on it. Added $2 \mathrm{~mL}$ of thionyl chloride to it drop wise from dropping funnel. This reaction mixture was stirred for $1 \mathrm{~h}$. To it, $2 \mathrm{~m} \mathrm{M}$ of indole-2-carboxylic acid was added in small fractions. This reaction mixture was stirred for $1 \mathrm{~h}$. at room temperature and then refluxed for $8 \mathrm{~h}$. TLC was checked in 5\% methanol: chloroform solvent system.
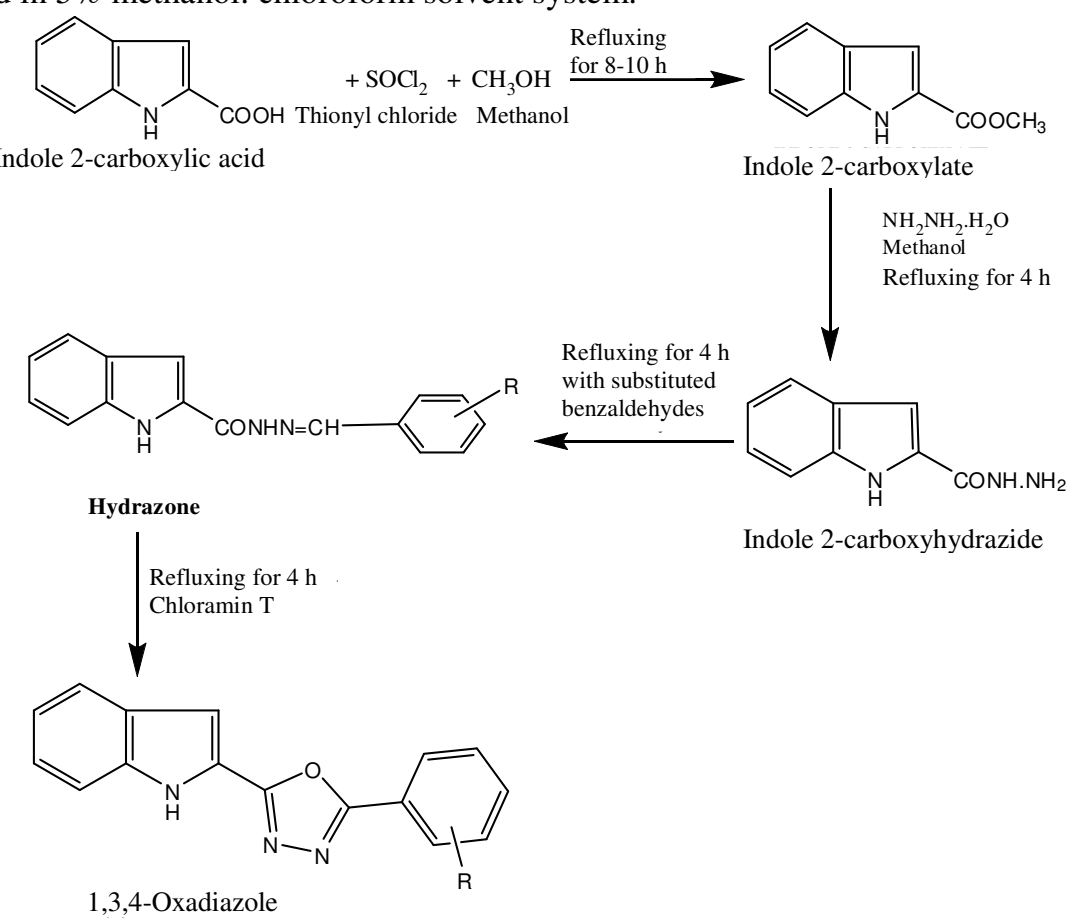

Scheme 1. synthesis of 1, 3, 4-oxadiazoles from indole-2-carboxylic acid.

Synthesis of indole-2-carboxyhydrazide (Acid hydrazide) from indole-2-carboxylate

$2 \mathrm{~m} \mathrm{M}$ of indole-2-carboxylate was dissolved in $10 \mathrm{~mL}$ methanol and to it; $2 \mathrm{~m} \mathrm{M}$ of hydrazine hydrate was added. A clear solution was obtained and this reaction mixture was refluxed for $5 \mathrm{~h}$. TLC was checked in 5\% methanol: chloroform solvent system.

\section{Synthesis of hydrazones from indole-2-carboxyhydrazides}

$1 \mathrm{~m} \mathrm{M}$ of indole-2-carboxyhydrazide was dissolved in $10 \mathrm{~mL}$ of methanol. To this reaction mixture, equimolar quantity of formaldehyde and substituted benzaldehydes (benzaldehyde, 2-chlorobenzaldehyde, salicylaldehyde, 3-chlorobenzaldehyde) was added. The clear solution obtained was refluxed for $6 \mathrm{~h}$. TLC was checked in 5\% methanol:chloroform solvent system. 


\section{Work-up}

Solvent was evaporated. The residue left was treated with saturated solution of sodium metabisulphite in order to remove unreacted benzaldehydes. The precipitates were filtered and recrystallised from absolute ethanol.

Synthesis of 1, 3, 4-oxadiazoles from respective hydrazones

$1 \mathrm{mM}$ Hydrazone $\mathrm{e}^{1-5}$ was dissolved in $20 \mathrm{~mL}$ of absolute ethanol. To it, $5 \mathrm{~m} \mathrm{M}$ chloramine $\mathrm{T}$ was added as an oxidizing agent, and was refluxed for $7 \mathrm{~h}$. This reaction will result in the synthesis of corresponding 1, 3, 4-oxadiazole. TLC was checked in 5\% methanol: chloroform solvent system.

Work-up

The reaction mixture was filtered off and the sodium chloride was separated. The solvent from the filtrate was evaporated and the precipitates obtained were recrystallised from absolute ethanol.<smiles>[R]CNc1cc2ccccc2[nH]1</smiles>

$\mathbf{R}_{1}=$ 5-Indole-1, 3, 4-oxadiazole.

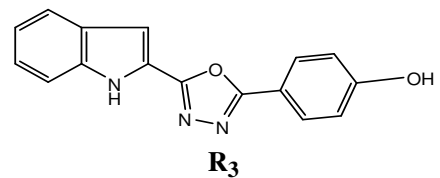

$\mathbf{R}_{3}$<smiles>Clc1cccc(-c2nnc(-c3cc4ccccc4[nH]3)o2)c1</smiles>

$\mathbf{R}_{2}$

$\mathbf{R}_{\mathbf{2}}=$ 2-(3-Chlorophenyl)-5-indole-1, 3, 4oxadiazole.

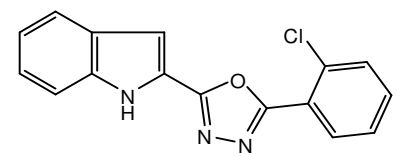

$\mathbf{R}_{4}$

$\mathbf{R}_{\mathbf{4}}=$ 2-(2-Chlorophenyl)-5-indole-1， 3, 4oxadiazole.

1, 3, 4-oxadiazole.<smiles>c1ccc(-c2nnc(-c3cc4ccccc4[nH]3)o2)cc1</smiles>

$\mathbf{R}_{5}$

$\mathbf{R}_{\mathbf{5}}=$ 2-Phenyl-5-indole-1, 3, 4-oxadiazole.

\section{Antimicrobial activity}

The solution of antibacterial agents $\mathrm{R}_{1}-\mathrm{R}_{5}$ (using dilution method of $10 \mathrm{mg} / \mathrm{mL}$ and 50 $\mathrm{mg} / \mathrm{mL}$ in $10 \%$ DMSO) were applied to the surface of the solid medium in the agar. Standard drugs used (Norfloxacin and Fluconazole) were taken in reported quantities, i.e. $1 \mathrm{mg} / \mathrm{mL}$ against following strains ${ }^{8-12}$ : MTCC 1573, MTCC 1430, MTCC 424, MTCC 441 and MTCC 2546.

\section{Results and Discussion}

The prepared compounds were subjected to physicochemical and spectral characterization. IR and mass spectra confirmed all the compounds. IR spectra were recorded on Shimadzu Infra-red spectrophotometer. Characteristic peaks observed were of $\mathrm{NH}-\mathrm{str}, \mathrm{C}=\mathrm{O},-\mathrm{CH}$ str, etc. Mass spectra were recorded on Jeol/ SX-102/ DA-600 FABMS spectroscopy from C.D.R.I, Lucknow. All mass spectra were correct except 1, 3, 4-oxadiazole(III), R3.Antimicrobial Activity was observed at $50 \mathrm{mg} / \mathrm{mL}$ of concentration. The antimicrobial 
activity was observed in compound $\mathbf{R}_{\mathbf{1}}$ (against B.subtilis and P. aeruginosa), $\mathbf{R}_{\mathbf{2}}$ (against S.aureus, E.coli and B. subtilis) and $\mathbf{R}_{\mathbf{5}}$ (against S.aureus). None of the compounds were found effective against $A$. niger. On the basis of spectral characterization it was concluded that 4 compounds out of 5 in the particular series have been synthesized correctly except compound $\mathbf{R}_{3}$ i.e. 1,3,4-oxadiazole(III). Out of these 4 compounds, only three were found effective against bacterial strains and none of the synthesized compound was found effective against fungal strain. The compounds which were active against bacterial strains were effective at a much higher concentration as compared to the standard drug, norfloxacin.

\section{Conclusions}

The entire study reveals that there is wide scope of modifications possible for 1, 3, 4oxadiazole ring system. Oxadiazole ring system could be incorporated into many more ring systems which itself have their own activity and could lead to more potent and highly active compounds. The emphasis should be laid on some other activities also, such as, antineoplastic, antiviral, pesticidal, anti-inflammatory, etc. Many new methods could be developed by using different solvents and substituents. Recent interest was shown by synthesizing the 1,3, 4-oxadiazoles by Microwave synthesis.

\section{Acknowledgement}

We are thankful to Dr. S. K. Saraf (Director, N.I.E.C, Lucknow) for their guidance and support and for providing all the possible facilities for the research work. Also we are thankful to Swati Laboratories, Greater Noida, U.P, for providing us with the gift sample of Fluconazole. My due regards to the Director, C.D.R.I, Lucknow for their kind assistance and support.

\section{References}

1. Arthur M and Courvalin P, Antimicrob Agents Chemother., 1993, 37, 1563.

2. Murray B, J Infect Dis., 1991, 163, 1185.

3. Gale E F, Cundliffe E and Reynolds P E, Richmond M H and Waring M J, The Molecular Basis of Antibiotic Action, $2^{\text {nd }}$ Ed. John Wiley \& Sons, New York, 1981, 473.

4. Foye O W, Principles of Medicinal Chemistry, $3^{\text {rd }}$ Ed, Published by Varghese Publishing House (P) Ltd., 1974, 676-736

5. Tripathi K D, Essential of Medical Pharmacology, $5^{\text {th }}$ Ed., Published by Jaypee Brothers Medical Publishers (P) Ltd., 2003, 627-629.

6. Khan M S Y, Chawla, Gita, Mueed and Asad M, Indian J Chem., 2004, 43B, 13021305

7. Silverstein R M and Webster X F, Spectrometric Identification of Organic Compounds, $6^{\text {th }}$ Ed., Published by John Wiley \& Sons (Asia) Pvt. Ltd, Singapore, 2005, 81-109.

8. Prescott M L, Harley P J and Klein A D, Microbiology, $6^{\text {th }}$ Ed., Published by McGraw-Hill Companies, NewYork, 2007, 93-97.

9. Abraham E. P, Chain E, Fletcher C M, Gardner A D, Heatley and Jennings M A, Lancet 2, 1941, 177.

10. Foster Woodruff, J Bacteriology, 1943, 46, 187.

11. Grove, Randall, Assay methods of antibiotics. Medical Encyclopedia, Inc New York, 1955, 171-175.

12. Indian Pharmacopoeia, 1996, Vol. II (P-Z), Published by the Controller of Publications, Delhi, A-100.

13. El-Masry A H Fahmy H H and Ali Abdelwahed S H, Molecules, 2000, 5, 1429-1438. 


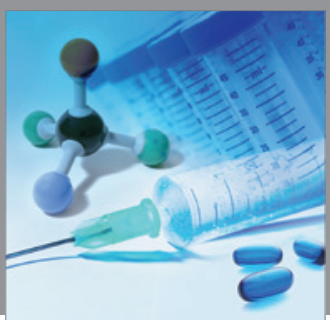

International Journal of

Medicinal Chemistry

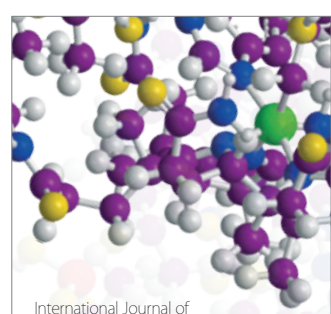

Carbohydrate Chemistry

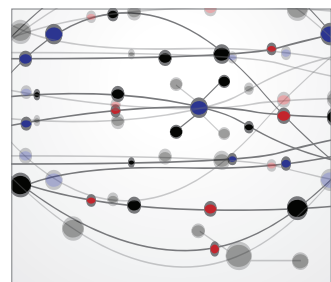

The Scientific World Journal
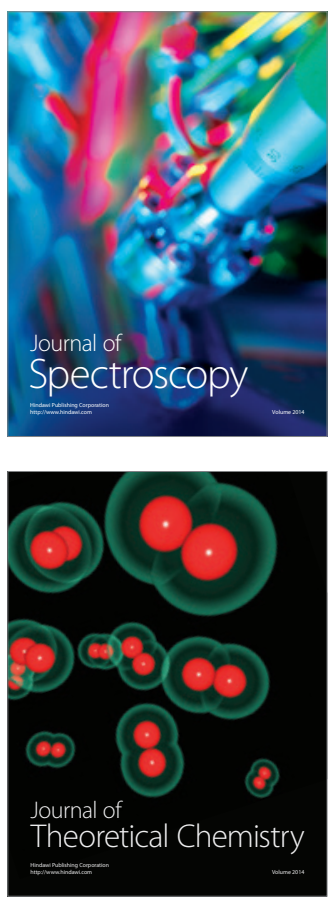
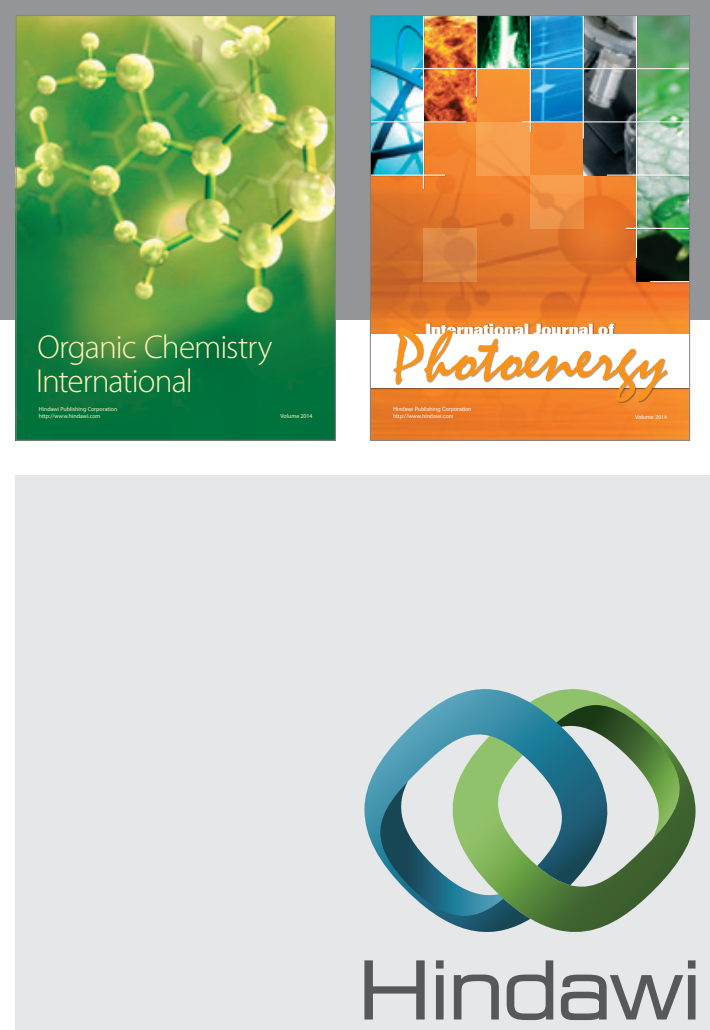

Submit your manuscripts at

http://www.hindawi.com
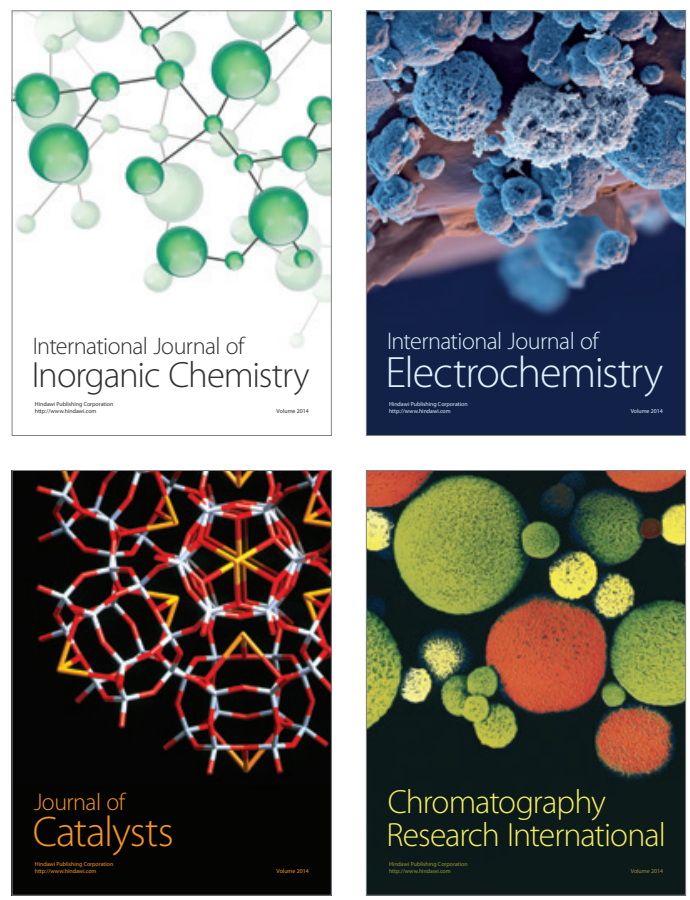
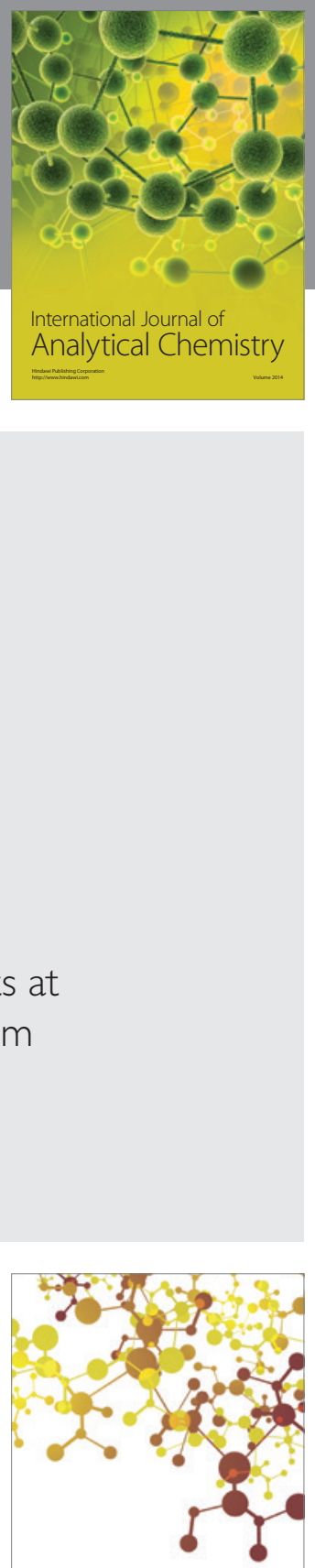

Journal of

Applied Chemistry
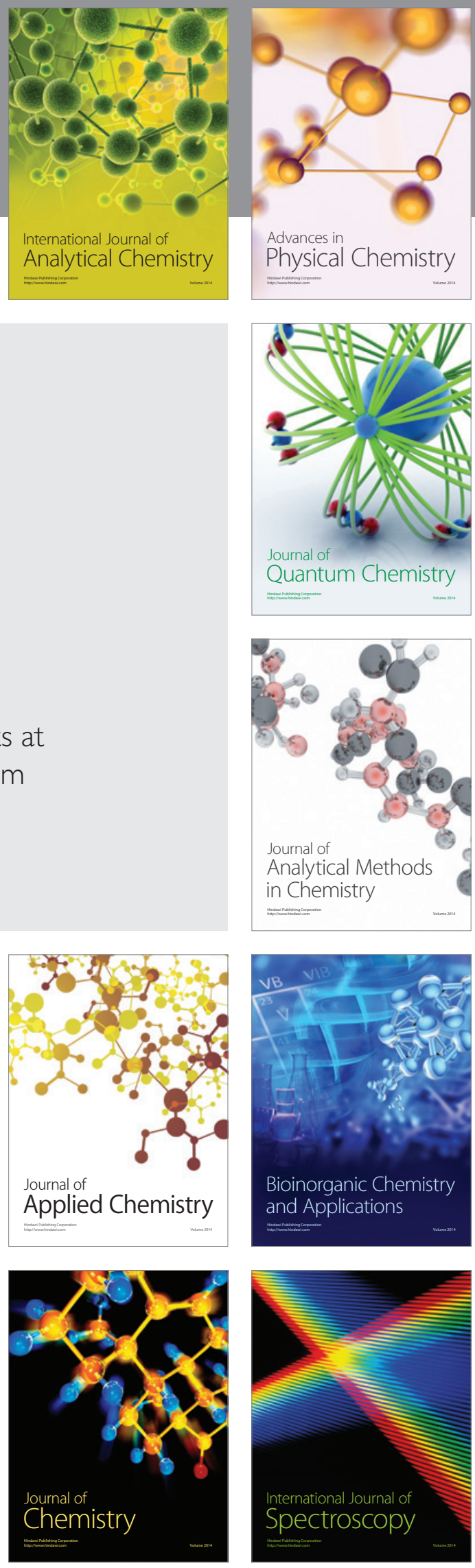